\title{
Suppressing Auger Recombination in Multiply Excited Colloidal Silicon Nanocrystals with Ligand-Induced Hole Traps
}

\author{
Gerard Michael Carroll, ${ }^{* \delta}$ Rens Limpens, ${ }^{\delta}$ Gregory F. Pach, Yaxin Zhai, Matthew C. Beard, \\ Elisa M. Miller, and Nathan R. Neale* \\ Chemistry and Nanoscience Center, National Renewable Energy Laboratory, 15013 Denver \\ West Parkway, Golden, Colorado 80401, United States \\ Email: mike.carroll@nrel.gov, nathan.neale@nrel.gov
}

\section{Silicon Nanocrystal Surface Chemical Environment and Chemical Reaction Mechansim: Analysis and Discussion}

\section{$\underline{\text { FTIR }}$}

Figure S1 displays the diffuse reflectance FTIR spectroscopy (DRIFTS) spectrum of $d=$ $3.8 \mathrm{~nm}$ hydride-terminated $\left(\mathrm{SiH}_{\mathrm{x}}\right) \mathrm{Si} \mathrm{NC}$ powder, where $* \mathrm{Si}$ denotes a surface $\mathrm{Si}$ atom. The spectrum exhibits the characteristic features associated with $* \mathrm{SiH}_{\mathrm{x}}$ stretching modes $(2000-2200$ $\left.\mathrm{cm}^{-1}\right),{ }^{*} \mathrm{SiH}_{2}$ scissor $\left(800-900 \mathrm{~cm}^{-1}\right)$ and ${ }^{*} \mathrm{SiH}_{2}$ wag $\left(600-750 \mathrm{~cm}^{-1}\right)$ modes; additional longitudinal acoustic phonon modes $\omega_{\mathrm{TO}}$ are evident at $490 \mathrm{~cm}^{-1}{ }^{1}$ Spectral signatures of surface oxide $\left(\mathrm{Si}-\mathrm{O}\right.$, ca. $1100 \mathrm{~cm}^{-1}$ ) are notably absent from these plasma-synthesized $\mathrm{SiH}_{\mathrm{x}}$-terminated NCs. To functionalize the Si NC surface, the $\mathrm{SiH}_{\mathrm{x}} \mathrm{NC}$ powder is reacted with either neat 1dodecene or 1-dodecanethiol at $140{ }^{\circ} \mathrm{C}$ with the radical initiator 1,1'azobis(cyclohexanecarbonitrile) in an Ar-filled glove box (the full synthetic procedure is outlined in the Supporting Information).

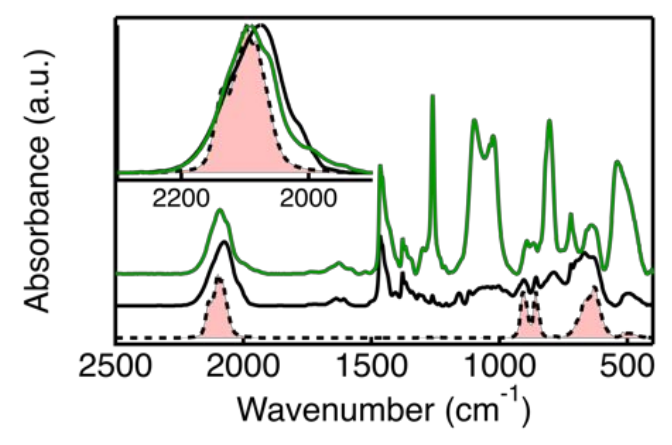

Figure S1. Diffuse reflectance FTIR spectra of $d=3.9 \mathrm{~nm}$ Silicon nanocrystals as synthesized (black dashed, red fill), and functionalized with 1-dodecanethiol (green) or 1-dodecene (black). The inset displays a zoomed in view of the ${ }^{*} \mathrm{Si}-\mathrm{H}_{\mathrm{X}}$ stretching region with all three spectra overlaid. 
The reaction mechanism through which these $\mathrm{SiH}_{\mathrm{x}} \mathrm{NCs}$ bind to alkenes, alkynes, amines, or alcohols requires first the abstraction of a surface silyl group $\left(\cdot \mathrm{SiH}_{3}\right)$ from the $\mathrm{Si} \mathrm{NC}{ }^{2}$ The silicon nanocrystal surface radical $\left({ }^{*} \mathrm{Si} \bullet\right)$ can then react with functional groups like alkenes through silylsilylation reaction mechanisms or amines and alcohols through homolytic cleavage of H-NHR or $\mathrm{H}-\mathrm{OR}$ bonds that result in * $\mathrm{Si}-\mathrm{E}$ bonds where $\mathrm{E}=\mathrm{CH}_{2} \mathrm{R}, \mathrm{NHR}$, or OR. ${ }^{2,3}$ Evidence for a similar - $\mathrm{SiH}_{3}$ abstraction with thiolate ligation comes from inspection of the $* \mathrm{SiH}_{\mathrm{x}}$ stretching region before and after reaction (Figure 1a, inset). The individual contributions from mono- $(* \mathrm{SiH}), \mathrm{di}-\left({ }^{*} \mathrm{SiH}_{2}\right)$, and trihydride $\left(* \mathrm{SiH}_{3}\right)$ absorption in order of increasing energy are easily resolved. Following the functionalization reaction with either 1-dodecene or 1-dodecanthiol, the high energy shoulder attributed to the ${ }^{*} \mathrm{SiH}_{3}$ (c.a. $2150 \mathrm{~cm}^{-1}$ ) disappears from the spectrum while the features assigned to $* \mathrm{SiH}_{2}$ and $* \mathrm{SiH}$ stretches remain but are shifted to lower energy. These spectra indicate that - $\mathrm{SiH}_{3}$ leaves for both $* \mathrm{Si}-\mathrm{CH}_{2} \mathrm{R}$ and $* \mathrm{Si}-\mathrm{SR}$ functionalization, and is likely the initiating step consistent with our previously detailed mechanistic study. ${ }^{2} \mathrm{We}$ note that the thiolate functionalization consistently produced NCs with greater oxidation compared to those with alkylfunctionalization as indicated by the $\mathrm{Si}-\mathrm{O}$ absorption at $1100 \mathrm{~cm}^{-1}$. The observed oxidative instability of Si NCs when terminated with alkylthiolate relative to alkyl is discussed in more detail below (Figure S2).

From the position of the $* \mathrm{SiH}_{\mathrm{x}}$ shifts with $* \mathrm{Si}-\mathrm{CH}_{2} \mathrm{R}$ or $* \mathrm{Si}-\mathrm{SR}$ ligation, the local electronic environment at the surface of the functionalized Si NC depends on the silicon-ligand bond identity. Whereas the $* \mathrm{SiH}_{2} / * \mathrm{SiH}$ stretching frequencies shift $\sim 25 \mathrm{~cm}^{-1}$ to lower energy from $2100 \mathrm{~cm}^{-1}$ to $2075 \mathrm{~cm}^{-1}$ with $* \mathrm{Si}-\mathrm{CH}_{2} \mathrm{R}$ functionalization, the same ${ }^{*} \mathrm{SiH}_{2} /{ }^{*} \mathrm{SiH}$ stretching modes with *Si-SR functionalization only shifts $\sim 10 \mathrm{~cm}^{-1}$ lower in energy to $2090 \mathrm{~cm}^{-1}$. This difference reflects changes in the electron donation ability from $-\mathrm{SR}$ compared to $-\mathrm{CH}_{2} \mathrm{R}$ which can be quantified by the Hammett parameter ( -0.07 for alkyl groups and 0.18 for alkylthiolates). ${ }^{4,5}$ This trend is consistent with our previous report comparing alkylamide, alkoxide and alkyl binding groups. ${ }^{3}$ Importantly, the ligand coverage density is not the cause of these shifts as both *Si-SR and ${ }^{*} \mathrm{Si}-\mathrm{CH}_{2} \mathrm{R}$ have similar areal ligand densities of $\sim 4$ ligands $\mathrm{nm}^{-2}$ (Table S1).

Figure $\mathrm{S} 2 \mathrm{a}$ plots DRIFTS data of $* \mathrm{Si}-\mathrm{SR}$ and $\mathrm{Si}-\mathrm{CH}_{2} \mathrm{R}$ NCs over a period of $\sim 8$ hours in normal atmospheric conditions. Both spectra display the characteristic $* \mathrm{SiH}_{\mathrm{x}}$ stretch from the remaining * $\mathrm{SiH}$ surface species following functionalization. The oxidation of the NCs at time zero - as quantified by the relative intensity of the ${ }^{*} \mathrm{SiO}_{\mathrm{x}}$ at $1100 \mathrm{~cm}^{-1}$ compared to the $* \mathrm{SiH}_{\mathrm{x}}-$ are similar for both ligand binding groups. As the air exposure time increases, however, a clear divergence between the ${ }^{*} \mathrm{Si}-\mathrm{SR}$ and the $* \mathrm{Si}-\mathrm{CH}_{2} \mathrm{R}$ samples becomes apparent. The ${ }^{*} \mathrm{SiO}_{\mathrm{x}}$ absorption for $* \mathrm{Si}-\mathrm{CH}_{2} \mathrm{R}$ displays very minor change over time ( $<10 \%$ of its original intensity), but the $* \mathrm{SiO}_{\mathrm{x}}$ absorption for $* \mathrm{Si}-\mathrm{SR}$ increases dramatically where the absorptive intensity eclipses the $* \mathrm{SiH}_{\mathrm{x}}$. Moreover, a new absorption feature at $2250 \mathrm{~cm}^{-1}$ appears at the high energy edge of the ${ }^{*} \mathrm{SiH}_{\mathrm{x}}$ stretching region in the ${ }^{*} \mathrm{Si}-\mathrm{SR}$ spetra which is assigned to oxygen backed ${ }^{*} \mathrm{SiH}_{\mathrm{x}}\left(\left[{ }^{*} \mathrm{O}\right]-\right.$ $\mathrm{SiH}_{\mathrm{x}}$ ). Interestingly, the $* \mathrm{SiH}_{\mathrm{x}}$ species remain largely in tact over the course of this oxidation experiment for both $* \mathrm{Si}-\mathrm{SR}$ and $* \mathrm{Si}-\mathrm{CH}_{2} \mathrm{R}$ samples indicating that while oxidation is clearly occurring, it does not appear to originate from the ${ }^{*} \mathrm{SiH}_{\mathrm{x}}$ sites. Rather the NC-ligand bonds themselves are the most prone to oxidation. 

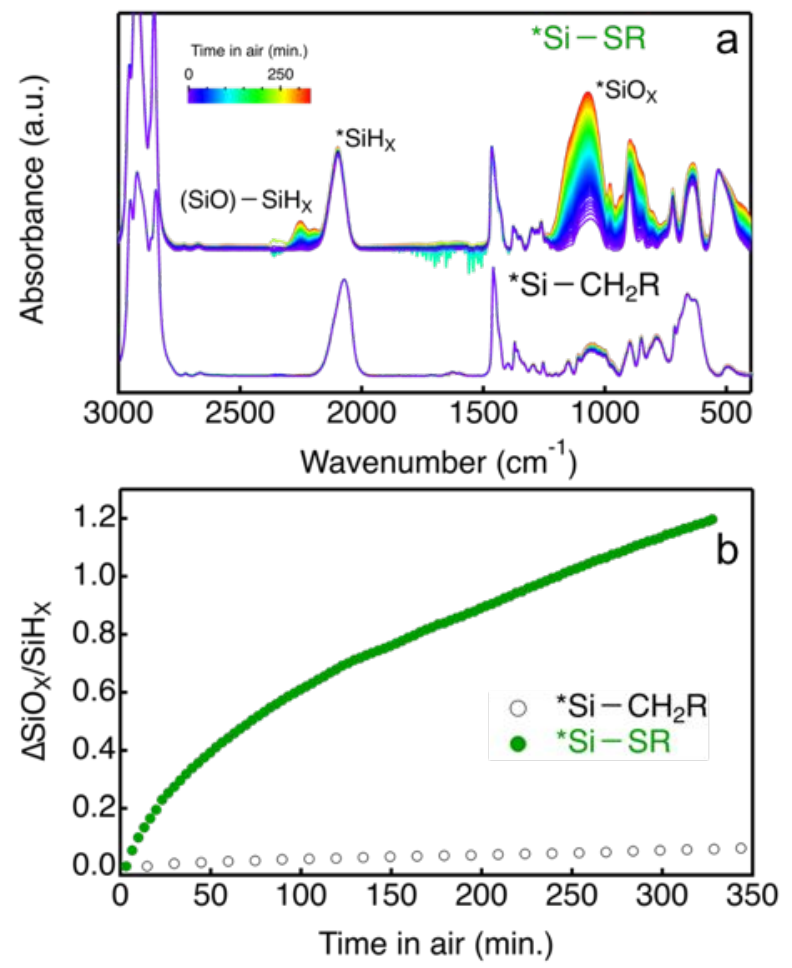

Figure S2. (a) Sequential DRIFT spectra of $d=3.8 \mathrm{~nm}$ Silicon NCs with thiolate, *Si-SR, (top) and alkyl, ${ }^{*} \mathrm{Si}-\mathrm{CH}_{2} \mathrm{R}$ (Bottom) surface functionalization while exposed to normal atmospheric conditions at room temperature. The color of the traces corresponds to the NCs time under air atmosphere which is indicated by the color bar. (b) Scatter plot of the change in intensity for the $\mathrm{SiO}_{\mathrm{X}}$ stretching mode at $1050 \mathrm{~cm}^{-1}$ divided by the intensity of the $\mathrm{SiH}_{\mathrm{X}}$ stretching mode for thiolate, *Si-SR (green), and alkyl, ${ }^{*} \mathrm{Si}-\mathrm{CH}_{2} \mathrm{R}$ (black) functionalized Si NCs.

\section{$\underline{{ }^{1} H N M R}$ and ICP-AES for Ligand Densities}

We have previously performed ${ }^{1} \mathrm{H}$ NMR on functionalized $\mathrm{Si} \mathrm{NCs}$ with alkyl $\left({ }^{*} \mathrm{Si}-\mathrm{CH}_{2} \mathrm{R}\right)$, amide $\left({ }^{*} \mathrm{Si}-\mathrm{NHR}\right)$, and alkoxide $\left({ }^{*} \mathrm{Si}-\mathrm{OR}\right)$ terminated silicon nanocrystals derived from non thermal plasma synthesis to quantify the surface ligand density. ${ }^{3}$ The method for ligand quantification of these thiolate $\left({ }^{*} \mathrm{Si}-\mathrm{SR}\right)$ terminated SiNCs is identical. ${ }^{1} \mathrm{H}$ NMR spectra were collected on $d=6.5 \mathrm{~nm} \mathrm{Si} \mathrm{NCs}$ and is plotted in figure $\mathrm{S} 3$ as well as the ${ }^{1} \mathrm{H}$ NMR spectrum of the neat dodecanethiol in toluene- $d_{8}$. Two broad resonances centered at 1 and $1.5 \mathrm{ppm}$ of the functionalized Si NC are apparent. These are the terminal methyl $\left(-\mathrm{CH}_{3}\right)$ and methylene groups $\left(\left(-\mathrm{CH}_{2}-\right)_{\mathrm{n}}\right)$ of the aliphatic dodecyl chain. Because of elongated $T_{2}$ relaxation time, NC size and surface heterogeneity, and inter-proton dipolar relaxation pathways, ${ }^{6-9}$ the peaks of these resonances are broadened compared to the neat ligand. 


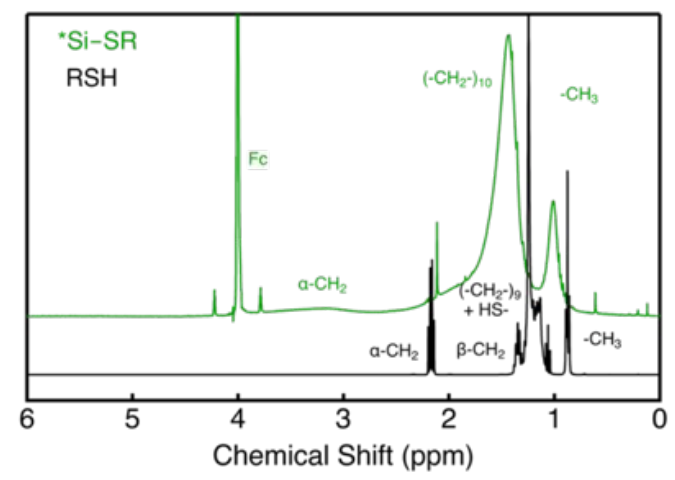

\begin{tabular}{|c|c|c|}
\hline Ligand & Density $\mathbf{~ m}^{-\mathbf{2}} \mathbf{( N M R )}$ & Density $\mathbf{~ m m}^{\mathbf{2}}$ (ICP-AES) \\
\hline${ }^{*} \mathrm{Si}-\mathrm{SR}$ & $3.9 \pm 0.8$ & 3.9 \\
\hline${ }^{*} \mathrm{Si}-\mathrm{CH}_{2} \mathrm{R}^{3}$ & $3.8 \pm 0.9^{3}$ & $4.6^{3}$ \\
\hline
\end{tabular}

Figure S3. ${ }^{1} \mathrm{H}$ NMR of (top panel) 1-dodecene (black) and $d=6.5 \mathrm{~nm} * \mathrm{Si}-\mathrm{CH}_{2} \mathrm{R}$ (grey), (middle panel) 1-dodecylamine (black) and $d=6.5 \mathrm{~nm} * \mathrm{Si}-\mathrm{NHR}$ (blue), and (bottom panel) 1-dodecanol (black) and $d=6.5 \mathrm{~nm} * \mathrm{Si}-\mathrm{OR}$ (red). The intense peak at $4.0 \mathrm{ppm}$ is ferrocene. The table is the average NC-ligand densities $\left(\mathrm{nm}^{-2}\right)$ of $d=6.5 \mathrm{~nm} \mathrm{Si} \mathrm{NCs}$. These values were determined from three independent syntheses for each ligand and the error bars represent $\pm 1 \sigma$ from the mean. The values of $* \mathrm{Si}-\mathrm{CH}_{2} \mathrm{R}$ were determined previously in ref. ${ }^{3}$.

To quantify the ligand density at the surface of these Si NCs, the methyl and methylene signals of each sample were integrated and ratiometrically compared to an internal ferrocene standard $(\mathrm{Fc}, 4 \mathrm{ppm})$. The average ligand densities from three unique $\mathrm{NC}$ syntheses are summarized in the Table in $\mathrm{S} 3$. Within experimental error, the ${ }^{*} \mathrm{Si}-\mathrm{SR}$ ligand density is equivalent to ${ }^{*} \mathrm{Si}-\mathrm{CH}_{2} \mathrm{R}$ at 3.9 and $3.8 \mathrm{~nm}^{-2}$, respectively. Inductively coupled plasma atomic emission spectroscopy (ICP-AES) measurements of the identical Si NC samples revealed ligand surface densities of $3.9 \mathrm{~nm}^{-2}$ as well.

\section{$\underline{X-R a y ~ p h o t o e l e c t r o n s p e c t r o s c o p y ~ m e a s u r e m e n t s ~}$}

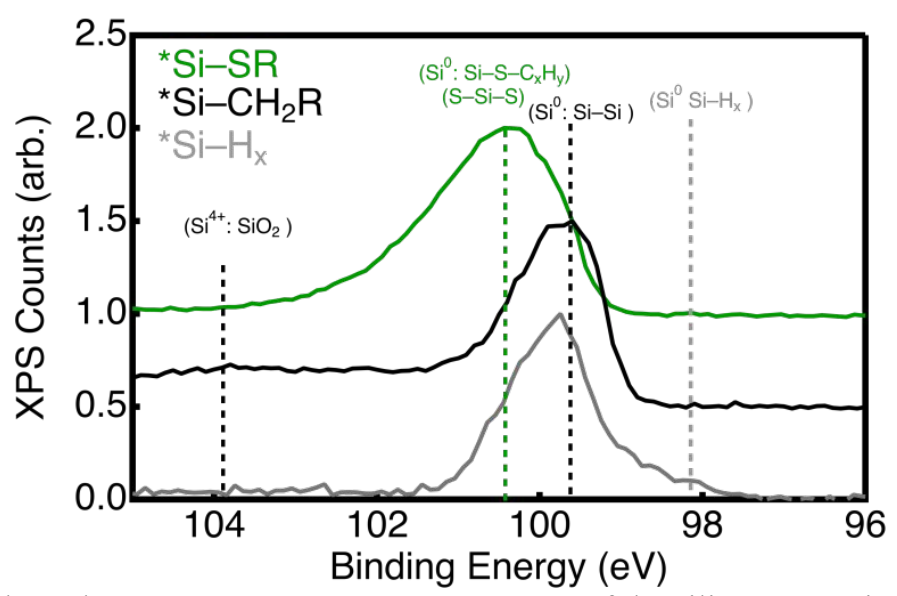

Figure S4. X-ray photoelectron spectroscopy measurements of the silicon $2 \mathrm{p}$ region for $d=6.4 \mathrm{~nm}$ hydride terminated (gray), dodecyl-terminated (black), and dodecylthiolate-terminated (green) silicon nanocrystals. These spectra have been normalized and offset vertically for clarity. 
The photoelectron spectra for alkyl, alkylthiolate, and hydride-terminated silicon is well documented and is characteristic of both the surface bonding moity as well as the silicon oxidation state. ${ }^{10,11}$ Figure S4 shows the XPS data for Si $2 p$ photoemission region of silicon nanocrystals with the two surface functionalizations used in this work, as well as the as prepared hydrideterminated surface. From this data, the $\mathrm{Si} 2 \mathrm{p}$ region for the ${ }^{*} \mathrm{Si}-\mathrm{H}_{\mathrm{x}}$ and ${ }^{*} \mathrm{Si}-\mathrm{CH}_{2} \mathrm{R}$ overlap with center of mass located at a binding energy of $99.4 \mathrm{eV}$. This peak position is in excellent agreement with $\mathrm{Si}^{0}$ terminated with highly nonpolar alkyl or hydride functionalities. A notable shoulder at $\sim 98 \mathrm{eV}$ is present in the ${ }^{*} \mathrm{Si}-\mathrm{H}_{\mathrm{x}}$ spectrum and is assigned to direct measurement of $\mathrm{Si}-\mathrm{H}_{\mathrm{x}}$ silicon. ${ }^{10}$ Consitent with the formation of an alkyl thiolate bond to the surface of silicon, the Si $2 p$ peak shifts to $100.4 \mathrm{eV} .{ }^{10}$ Whereas a shoulder is observed in Si wafer measurements, a shift of the entire peak position indicates that the electronic effect the sulfur capping group has on the silicon nanocrystal penetrates the entire volume of the crystal and not just the surface Si atoms. These results are clear evidence that Scheme 1 of the main text is an accurate representation of the thiolate (and alkyl) terminated Si NCs. We note that evidence of a small amount of oxidation $\left(\mathrm{Si}^{4+}\right)$ is present in the alkyl-terminated at $104 \mathrm{eV}$, but is absent in both the ${ }^{*} \mathrm{Si}-\mathrm{H}_{\mathrm{x}}$ and ${ }^{*} \mathrm{Si}-\mathrm{SR}$ samples.

\section{Powder X-ray diffraction and Scherrer Broadening Analysis}

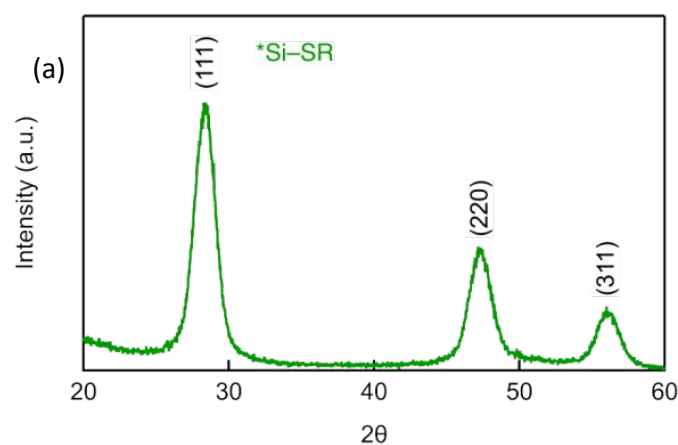

(c)

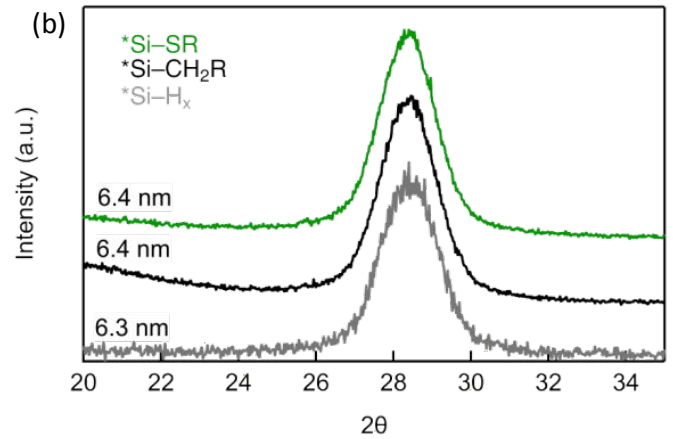

c)

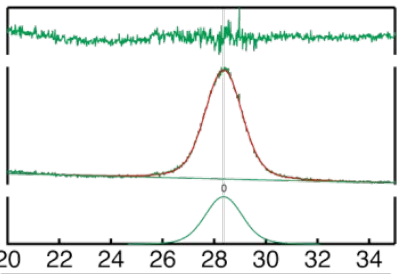

(d)
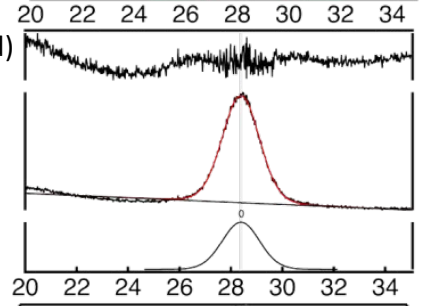

(e)
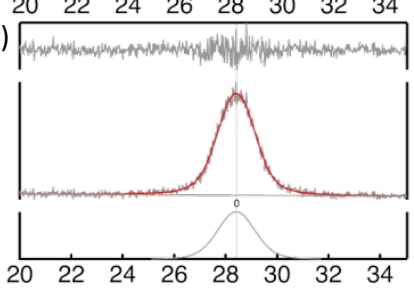

Figure S5. (a) Powder X-ray diffraction pattern for *Si-SR with the corresponding Miller indeces labeled for the diamond cubic structure of crystalline silicon. (b) The diffraction corresponding to the 111 plane for *Si-SR (green), * ${ }^{*} i-\mathrm{CH}_{2} \mathrm{R}$ (black), and ${ }^{*} \mathrm{SiH}_{\mathrm{x}}$ (gray) terminated $\mathrm{Si} \mathrm{NP}$ powers. Scherrer broadening analysis for the same samples is shown in (c), (d), and (e). The fit for each sample is shown in red in the middle panel and of the same color on the bottom panel. The top panel shows the residual to the fit.

Figure S5 shows an example of the Scherrer broadening analysis used to determine some Si NP sizes befor and after NP functionalization. Within the error of the measurement, we detect no change in the NP size upon functionalization with different surface ligands. 


\section{Single Exciton Transient Absorption Measurements}

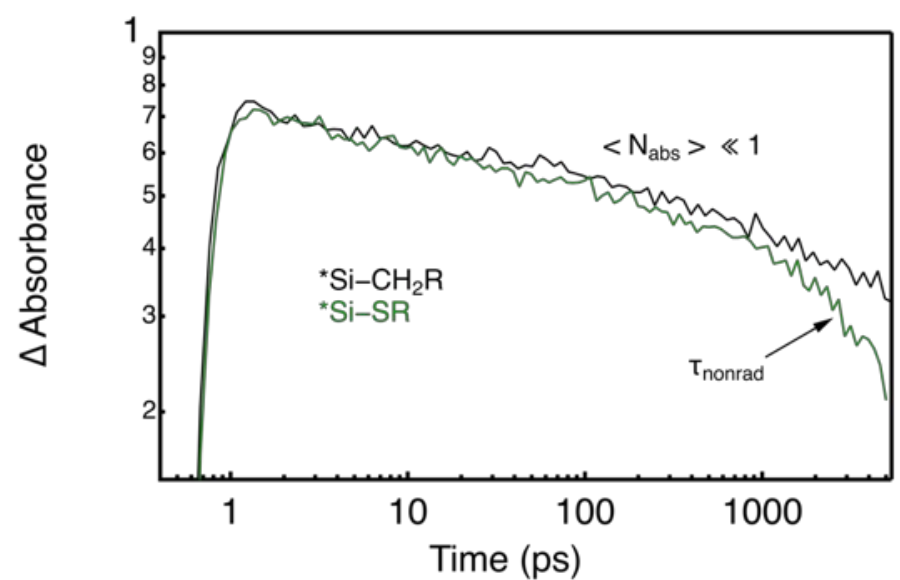

Figure S6: Transient absorption of singly excited $d=3.9 \mathrm{~nm} \mathrm{Si} \mathrm{NCs}$ with $* \mathrm{Si}-\mathrm{CH}_{2} \mathrm{R}$ (black) and *Si-SR (green) surface termination. The photoexcitation was $400 \mathrm{~nm}$ and the probe wavelength was $1200 \mathrm{~nm}$.

In this experiment, a VIS-pump beam with a wavelength of $\lambda_{\text {pump }}=600 \mathrm{~nm}$ or $400 \mathrm{~nm}$ photoexcites $\mathrm{e}^{-}-\mathrm{h}^{+}$pairs which are subsequently monitored using a probe beam of $\lambda_{\text {probe }}=1200 \mathrm{~nm}$. Our white-light continuum experimental configuration probes a wavelength range of $\lambda_{\text {probe }}=$

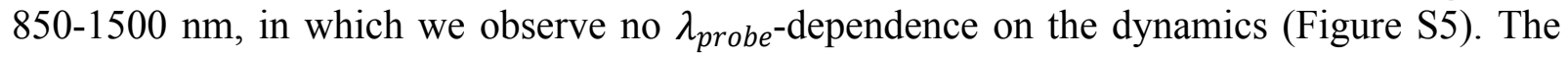
good signal-to-noise trace of $\lambda_{\text {probe }}=1200 \mathrm{~nm}$ is therefore representative for the whole spectrum. From these data, the decay dynamics are nearly identical between $t=1 \mathrm{ps}$ and $1 \mathrm{~ns}$ for *Si-SR and ${ }^{*} \mathrm{Si}-\mathrm{CH}_{2} \mathrm{R} ; \sim 50 \%$ of the photoinduced absorption intensity corresponding to bound excitons is lost within $\sim 1 \mathrm{~ns}$. After $1 \mathrm{~ns}$, the photoinduced absorption intensity of the *Si-SR deviates from the ${ }^{*} \mathrm{Si}-\mathrm{CH}_{2} \mathrm{R}$ which we attribute to non-radiative recombination in the $* \mathrm{Si}-\mathrm{SR}$ Si NCs through surface-realted mid-gap states, consistent with the our steady-state and TRPL measurements. 

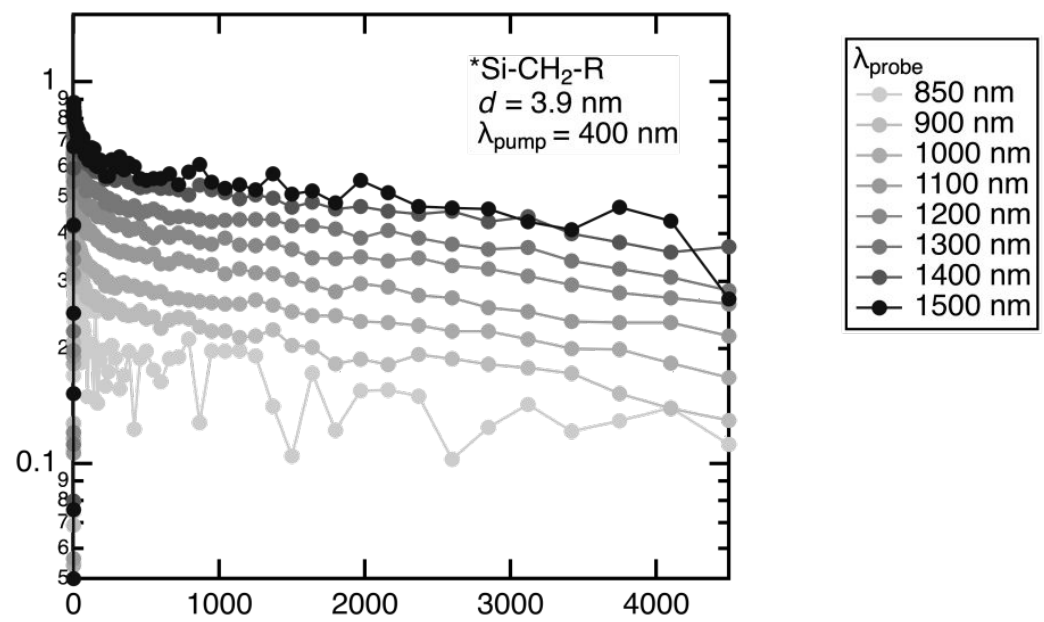

Figure S7. (a) Transient absorption measurements for $d=3.9 \mathrm{~nm}$ Si NCs with dodecyl-surface functionalization at varied probe wavelengths. The data show that the decay dynamics are independent of probe region. The data have been offset in intensity for clarity.

\section{Multiple Exciton Transient Absorption Measurements}

For measurements that consisted of more than one absorbed photon per silicon nanocrystal a pump fluence-dependent experiment was carried out. In the limit of multiple absorbed photons per Si NC, a fast component in the transient trace became visible (figure S6). This fast component is a combination of double, triple, quadruply etc. excited Si NCs and the appearance of this additional signal is an indication of more than one excitation per Si NC. The slowest time component of this fast signal is attributed to the Auger recombination of doubly excited Si NCs. ${ }^{12}$ Because we are not interested in the multiple exciton generation efficiency in this study, we did not stir the samples during measurement. ${ }^{13}$

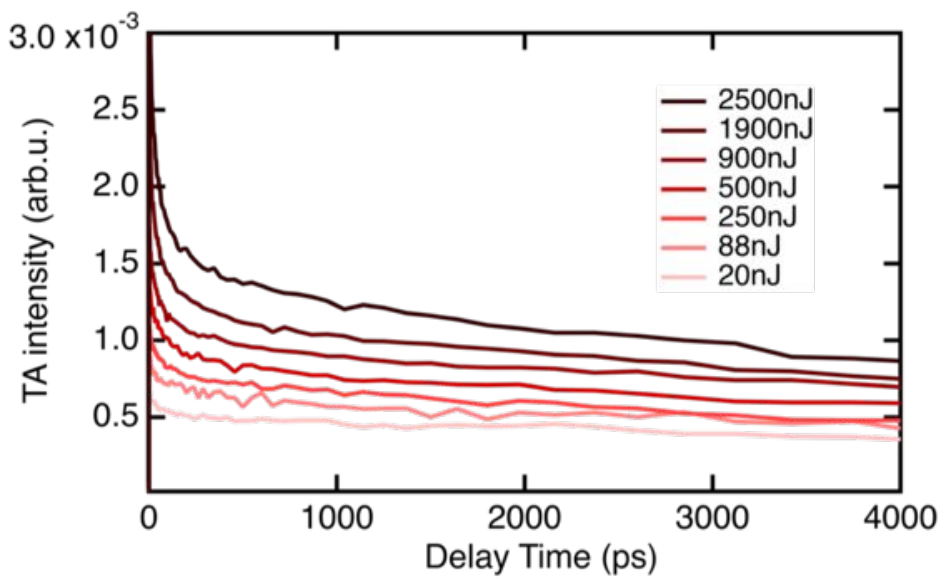

Figure S8: Fluence-dependent transient absorption on $d=3.9 \mathrm{~nm} * \mathrm{Si}-\mathrm{CH}_{2} \mathrm{R}$ terminated $\mathrm{Si} \mathrm{NCs}$. The photoexcitation was $600 \mathrm{~nm}$ and the probe wavelength was $1200 \mathrm{~nm}$. 

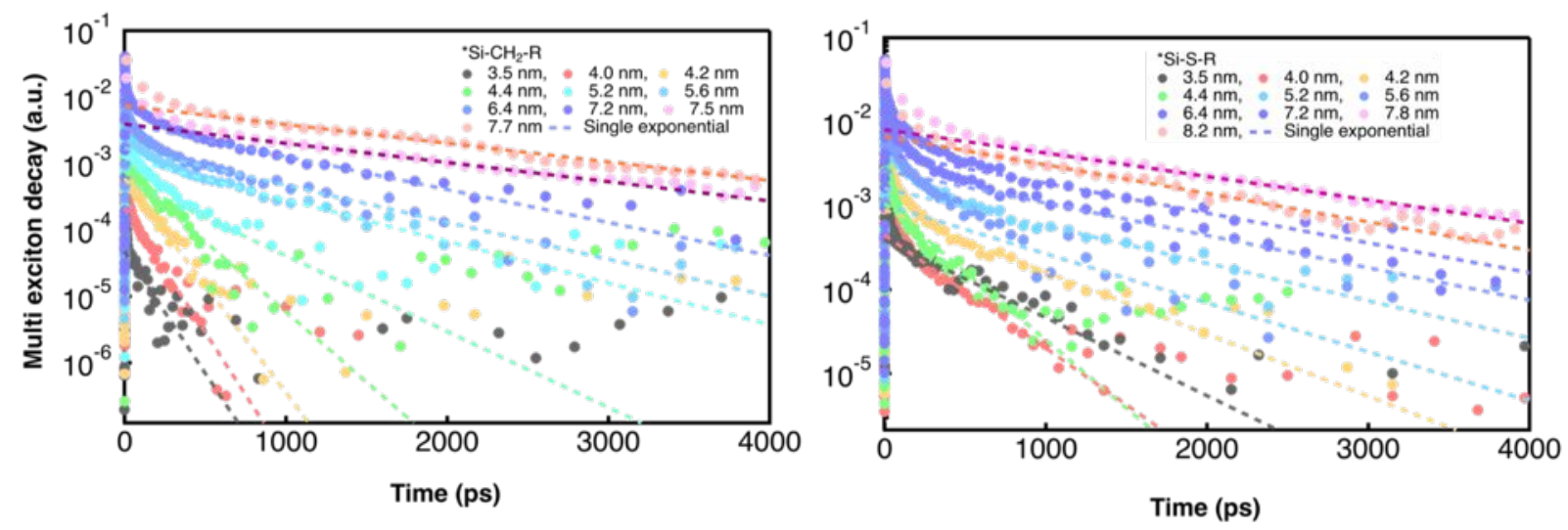

Figure S9. Multi exciton decay traces of * ${ }^{*} i-\mathrm{CH}_{2} \mathrm{R}$ (Left) and $* \mathrm{Si}-\mathrm{SR}$ (Right) $\mathrm{Si} \mathrm{NCs}$ of $\mathrm{D}_{\mathrm{NC}}=3.5-7.2 \mathrm{~nm}$. The dashed lines show the fits to the data and the extracted lifetime are the $\tau_{x x}$ values reported in the main text.

Photoluminescence Constants and Radiative Decay Rates

\begin{tabular}{|c|c|c|c|c|}
\hline \multicolumn{5}{|c|}{${ }^{*} \mathrm{Si}-\mathrm{CH}_{2} \mathrm{R}$ terminated Si NCs } \\
\hline Si NC diameter & $\tau_{P L, 1}$ & $\tau_{P L, 2}$ & PL peak energy & FWHM \\
\hline $3.7 \mathrm{~nm}$ & $12 \mu \mathrm{s}$ & $91 \mu \mathrm{s}$ & 1.53 & $190 \mathrm{meV}$ \\
\hline $4.2 \mathrm{~nm}$ & $12 \mu \mathrm{s}$ & $115 \mu \mathrm{s}$ & 1.46 & $240 \mathrm{meV}$ \\
\hline $5.2 \mathrm{~nm}$ & $14 \mu \mathrm{s}$ & $132 \mu \mathrm{s}$ & 1.36 & $240 \mathrm{meV}$ \\
\hline $7.6 \mathrm{~nm}$ & $66 \mu \mathrm{s}$ & $237 \mu \mathrm{s}$ & 1.26 & $250 \mathrm{meV}$ \\
\hline
\end{tabular}

\begin{tabular}{|c|c|c|c|c|}
\hline \multicolumn{5}{|c|}{$*$ Si-SR terminated Si NCs } \\
\hline Si NC diameter & $\tau_{P L, 1}$ & $\tau_{P L, 2}$ & PL peak energy & FWHM \\
\hline $3.7 \mathrm{~nm}$ & $91 \mathrm{~ns}$ & $702 \mathrm{~ns}$ & $1.62 \mathrm{eV}$ & $450 \mathrm{meV}$ \\
\hline $4.2 \mathrm{~nm}$ & $76 \mathrm{~ns}$ & $524 \mathrm{~ns}$ & $1.46 \mathrm{eV}$ & $320 \mathrm{meV}$ \\
\hline $5.2 \mathrm{~nm}$ & $70 \mathrm{~ns}$ & $625 \mathrm{~ns}$ & $1.35 \mathrm{eV}$ & $240 \mathrm{meV}$ \\
\hline $7.6 \mathrm{~nm}$ & $83 \mathrm{~ns}$ & $717 \mathrm{~ns}$ & $1.25 \mathrm{eV}$ & $250 \mathrm{meV}$ \\
\hline
\end{tabular}

Table S1. Photoluminescence decay rate constants, peak positions, and full-width at half maximum for four sizes of silicon nanocrystals with ${ }^{*} \mathrm{Si}-\mathrm{CH}_{2} \mathrm{R}$ (top) and ${ }^{*} \mathrm{Si}-\mathrm{SR}$ (bottom) surface functionalization.

The radiative rate constant of exciton recombination is related to the observed PL decay rate by:

$$
1 / \tau^{1} /_{\tau_{r}}+1 / \tau_{n r}
$$


Where $\tau$ is the observed PL decay rate, $\tau_{r}$ is the radiative decay rate and $\tau_{n r}$ is the nonradiative decay rate. The PL quantum efficiency $(\eta)$ may be expressed as the branching ratio of the radiatve and non-radiative decay rate contants:

$$
\eta=\frac{1 / \tau_{r}}{1 / \tau_{r}+1 / \tau_{n r}}
$$

Eq. S3

Substitution of Eq. S3 into S4 yeilds a solution to the radiative decay rate constants for these silicon nanocrystals. The measured quantum efficiency of $* \mathrm{Si}-\mathrm{SR}$ terminated $\mathrm{Si} \mathrm{NCs}$ with $d$ $>5 \mathrm{~nm}$ were found to be low enough that we cannot be confident in the values. We therefore stress that, while we report values for the PLQY of these *Si-SR NCs, these are estimations and have a large error. Nevertheless, estimating the quantum efficiency helps understand the radiative rate constant changes associated with different surface functionalizations. Here, due to the error of the measurements, we do not believe the radiative rates differ considerably between the two surface terminations, and posit the differences in $\tau_{2}$ are simply related to the an increase in $\tau_{n r}$. The calculated radiative rates of the silicon NCs in Table S2 are shown below:

\begin{tabular}{|c|c|c|c|}
\hline \multicolumn{4}{|c|}{$* \mathrm{Si}-\mathrm{CH}_{2} \mathrm{R}$ terminated Si NCs } \\
\hline Si NC diameter & $\tau 2$ & PLQY $(\%)$ & $\tau_{r}$ \\
\hline $3.7 \mathrm{~nm}$ & $91 \mu \mathrm{s}$ & 10 & $0.9 \mathrm{~ms}$ \\
\hline $4.2 \mathrm{~nm}$ & $115 \mu \mathrm{s}$ & 10 & $1.15 \mathrm{~ms}$ \\
\hline $5.2 \mathrm{~nm}$ & $132 \mu \mathrm{s}$ & 10 & $1.32 \mathrm{~ms}$ \\
\hline $7.6 \mathrm{~nm}$ & $237 \mu \mathrm{s}$ & 10 & $2.37 \mathrm{~ms}$ \\
\hline
\end{tabular}

\begin{tabular}{|c|c|c|c|}
\hline \multicolumn{4}{|c|}{${ }^{*}$ Si-SR terminated Si NCs } \\
\hline Si NC diameter & $\tau 2$ & PLQY $(\%)$ & $\tau_{r}$ \\
\hline $3.7 \mathrm{~nm}$ & $702 \mathrm{~ns}$ & 1 & $0.07 \mathrm{~ms}$ \\
\hline $4.2 \mathrm{~nm}$ & $524 \mathrm{~ns}$ & $0.5^{*}$ & $0.01 \mathrm{~ms}$ \\
\hline $5.2 \mathrm{~nm}$ & $625 \mathrm{~ns}$ & $0.1^{*}$ & $0.6 \mathrm{~ms}$ \\
\hline $7.6 \mathrm{~nm}$ & $717 \mathrm{~ns}$ & $0.1 *$ & $0.7 \mathrm{~ms}$ \\
\hline
\end{tabular}

Table S2. Estimated radiative recombination rate constants for four silicon nanocrystal sizes with ${ }^{*} \mathrm{Si}-\mathrm{CH}_{2} \mathrm{R}$ (top) and ${ }^{*} \mathrm{Si}-\mathrm{SR}$ (bottom) surface functionalization. The PLQY for the ${ }^{*} \mathrm{Si}-\mathrm{CH}_{2} \mathrm{R}$ terminated Si NCs are the average from our previous measurements. ${ }^{3}$ The $*$ denotes that the measured PLQY was too low to be confident in the assigned values. These values are therefore an estimate and may deviate considerably from the real PLQY values.

Time-Resolved THz Spectroscopy Analysis 
Photomodulation of the THz transmitted field, $\Delta E$, is sensitive to changes in the electric susceptibility, $\Delta \chi$, upon photoexcitation of the sample ${ }^{14}$ this can be expressed as: ${ }^{15}$

$$
\frac{-\Delta E(\omega ; t)}{E(\omega)}=\frac{i \omega\langle\Delta \chi(\omega ; t)\rangle z V_{f}}{c \beta \kappa}
$$

where \langle\rangle indicates an average over all Si NC orientations, $\mathrm{c}$ is the speed of light, $\mathrm{z}$ is the optical penetration depth, $\mathrm{V}_{\mathrm{f}}$ is the volume fraction of the Si NCs in the photoexcitation volume, and $\Delta \chi$ $(\omega ; \mathrm{t})$ is the frequency-dependent change in susceptibility where $\omega$ is the THz probe frequency. The parameter $\beta$ takes into account the transmission of the THz pulse through a thick sample with bulk-like absorption and for sphereical nanocrystals is: ${ }^{16,17}$

$$
\beta=\frac{\left(n_{\text {toluene }}+n_{\text {quartz }}\right)^{2}}{\left[2 n_{\text {toluene }}\left(1-e^{L / z}\right)\right]}
$$

Eq. S5

Where $n_{\text {toluene }}$ and $n_{\text {quartz }}$ are the index of refraction for toluene and quartz, and L is the thickness of the cuvette. The parameter $\kappa$ accounts for the different dielectric constants of the photoexcited Si NCs and the toluene matrix: ${ }^{16}$

$$
\kappa=\frac{2 \varepsilon_{\text {toluene }}+\varepsilon_{\text {SiNC }}}{3 \varepsilon_{\text {SiNC }}^{2}}
$$

Eq. S6

For a derivation and more detailed discussion on the origins of these equations see ref. ${ }^{15}$ and ${ }^{16}$. The polarizability, $\alpha_{x}$, can be approximated to the susceptibility through:

$$
\Delta \chi=\alpha_{\mathrm{X}} N(N=\text { carrier density }) .
$$




\section{References:}

1. Brodsky, M. H.; Cardona, M.; Cuomo, J. J., Infrared and Raman spectra of the siliconhydrogen bonds in amorphous silicon prepared by glow discharge and sputtering. Phys. Rev. $B$ 1977, 16 (8), 3556-3571.

2. Wheeler, L. M.; Anderson, N. C.; Palomaki, P. K. B.; Blackburn, J. L.; Johnson, J. C.; Neale, N. R., Silyl Radical Abstraction in the Functionalization of Plasma-Synthesized Silicon Nanocrystals. Chem. Mater. 2015, 27 (19), 6869-6878.

3. Carroll, G. M.; Limpens, R.; Neale, N. R., Tuning Confinement in Colloidal Silicon Nanocrystals with Saturated Surface Ligands. Nano Lett. 2018, 18 (5), 3118-3124.

4. Johnson, C. D., The Hammett Equation. Cambridge University Press: New York, 1973; $p$ 208.

5. Hansch, C.; Leo, A.; Taft, R. W., A survey of Hammett substituent constants and resonance and field parameters. Chem. Rev. 1991, 91 (2), 165-195.

6. Anderson, N. C.; Hendricks, M. P.; Choi, J. J.; Owen, J. S., Ligand Exchange and the Stoichiometry of Metal Chalcogenide Nanocrystals: Spectroscopic Observation of Facile MetalCarboxylate Displacement and Binding. J. Am. Chem. Soc. 2013, 135, 18536.

7. Fritzinger, B.; Capek, R. K.; Lambert, K.; Martins, J. C.; Hens, Z., Utilizing Self-Exchange To Address the Binding of Carboxylic Acid Ligands to CdSe Quantum Dots. J. Am. Chem. Soc. 2010, 132 (29), 10195-10201.

8. Hens, Z.; Martins, J. C., A Solution NMR Toolbox for Characterizing the Surface Chemistry of Colloidal Nanocrystals. Chem. Mater. 2013, 25 (8), 1211-1221.

9. Morris-Cohen, A. J.; Malicki, M.; Peterson, M. D.; Slavin, J. W. J.; Weiss, E. A., Chemical, Structural, and Quantitative Analysis of the Ligand Shells of Colloidal Quantum Dots. Chem. Mater. 2013, 25 (8), 1155-1165.

10. Lai, Y.-H.; Yeh, C.-T.; Yeh, C.-C.; Hung, W.-H., Thermal Reactions of Methanethiol and Ethanethiol on Si(100). J. Phys. Chem. B 2003, 107 (35), 9351-9356.

11. Bhartia, B.; Puniredd, S. R.; Jayaraman, S.; Gandhimathi, C.; Sharma, M.; Kuo, Y.-C.; Chen, C.-H.; Reddy, V. J.; Troadec, C.; Srinivasan, M. P., Highly Stable Bonding of Thiol Monolayers to Hydrogen-Terminated Si via Supercritical Carbon Dioxide: Toward a Super Hydrophobic and Bioresistant Surface. ACS Appl. Mater. Interfaces 2016, 8 (37), 24933-24945. 12. Klimov, V. I.; Mikhailovsky, A. A.; McBranch, D. W.; Leatherdale, C. A.; Bawendi, M. G., Quantization of Multiparticle Auger Rates in Semiconductor Quantum Dots. Science 2000, 287 (5455), 1011.

13. McGuire, J. A.; Sykora, M.; Joo, J.; Pietryga, J. M.; Klimov, V. I., Apparent Versus True Carrier Multiplication Yields in Semiconductor Nanocrystals. Nano Lett. 2010, 10 (6), 2049-2057. 14. Kindt, J. T.; Schmuttenmaer, C. A., Theory for determination of the low-frequency timedependent response function in liquids using time-resolved terahertz pulse spectroscopy. $J$. Chem. Phys. 1999, 110 (17), 8589-8596. 
15. Beard, M. C.; Turner, G. M.; Schmuttenmaer, C. A., Transient photoconductivity in GaAs as measured by time-resolved terahertz spectroscopy. Phys. Rev. B 2000, 62 (23), 15764-15777. 16. Bergren, M. R.; Palomaki, P. K. B.; Neale, N. R.; Furtak, T. E.; Beard, M. C., SizeDependent Exciton Formation Dynamics in Colloidal Silicon Quantum Dots. ACS Nano 2016, 10 (2), 2316-2323.

17. Bergren, M. R.; Kendrick, C. E.; Neale, N. R.; Redwing, J. M.; Collins, R. T.; Furtak, T. E.; Beard, M. C., Ultrafast Electrical Measurements of Isolated Silicon Nanowires and Nanocrystals. J. Phys. Chem. Lett. 2014, 5 (12), 2050-2057. 